\section{JTI}

JOURNAL OF

TRAUMA AND INJURY

Received: February 16, 2021

Revised: March 17, 2021

Accepted: March 24, 2021

\section{Correspondence to}

Gil Jae Lee, M.D., Ph.D.

Department of Traumatology, Gachon University College of Medicine, 38-13

Dokjeom-ro 3beon-gil, Namdong-gu, Incheon 21565, Korea

Tel: $+82-32-460-3010$

Fax: +82-32-460-2372

E-mail: nonajugi@gilhospital.com

\title{
Comparison of Resting Energy Expen- diture Using Indirect Calorimetry and Predictive Equations in Trauma Patients: A Pilot Study
}

\author{
Dae Sung Ma, M.D ${ }^{1}$, Gil Jae Lee, M.D., Ph.D. ${ }^{2}$ \\ ${ }^{1}$ Trauma Center, Department of Cardiovascular Surgery, Dankook University Hospital, \\ Cheonan, Korea \\ ${ }^{2}$ Department of Trauma Surgery, Trauma Center, Gachon University Gil Medical Center, \\ Incheon, Korea
}

Purpose: Nutritional therapy in the intensive care unit is an essential factor for patient progress. The purpose of this study was to compare resting energy expenditure (REE) calculated by prediction equations (PEs) to the REE measured by indirect calorimetry (IC) in trauma patients.

Methods: Patients admitted to the trauma intensive care unit who received mechanical ventilation between January and December 2015 were enrolled. REE was measured by IC (CCM Express, MGC Diagnostics) and calculated by the following PEs: Harris-Benedict, Fleisch, Robertson and Reid, Ireton-Jones, and the maximum value $(25 \mathrm{kcal} / \mathrm{kg} /$ day) of the European Society for Clinical Nutrition and Metabolism (ESPEN). All patients were ventilated at a fraction of inspired oxygen $\left(\mathrm{FiO}_{2}\right)$ below $60 \%$.

Results: Of the 31 patients included in this study, 24 (77.4\%) were men and seven (22.6\%) were women. The mean age of the patients was $49.7 \pm 13.2$ years, their mean weight was $68.1 \pm 9.6 \mathrm{~kg}$, and their mean Injury Severity Score was $26.1 \pm 11.3$. The mean respiratory quotient on IC was $0.93 \pm 0.19$, and their mean $\mathrm{FiO}_{2}$ was $38.72 \% \pm 6.97 \%$. The mean REE measured by IC was $2,146 \pm 444.36 \mathrm{kcal} /$ day, and the mean REE values calculated by the PEs were 1,509.39 $\pm 205.34 \mathrm{kcal} /$ day by the Harris and Benedict equation, $1,509.39 \pm 154.33$ $\mathrm{kcal} /$ day by the Fleisch equation, and $1,443.39 \pm 159.61 \mathrm{kcal} /$ day by the Robertson and Reid equation. The Ireton-Jones equation yielded a higher value $(2,278.90 \pm 202.35 \mathrm{kcal} /$ day), which was not significantly different from the value measured using IC ( $p=0.53)$. The ESPEN maximum value $(1,704.03 \pm 449.36 \mathrm{kcal} /$ day $)$ was lower, but this difference was likewise not significant $(p=0.127$ ).

Conclusions: The REE measured by IC was somewhat higher than that calculated using PEs. Further studies are needed to determine the proper nutritional support for trauma patients.

Keywords: Energy metabolism; Calorimetry, indirect; Wounds and injuries 


\section{INTRODUCTION}

Nutritional therapy for critically ill patients is an essential factor for patient progress. Especially in trauma patients, changes in energy metabolism, such as hypermetabolism, result in undernutrition or overnutrition if proper nutritional support is not supplied [1]. Undernutrition has been found to be related to poor wound healing, an increased risk of infections, impaired muscle function, and reduced cardiac and respiratory reserve [2]. Overnutrition, in contrast, may induce respiratory compromise, cause hepatic dysfunction, and increase the risk of infection [3-5].

Currently, indirect calorimetry (IC) is the accepted gold standard for measuring resting energy expenditure (REE) [6]. Several studies have shown that IC is more accurate than predictive equations (PEs) in determining the energy needs of critically ill patients, including traumatized patients $[5,7,8]$. However, measuring REE by IC is not always available, as it requires expensive equipment and trained personnel. Thus, many critical care physicians still rely on various PEs to estimate the caloric needs of patients. These PEs, such as the Harries-Benedict, Fleisch, Robertson and Reid, Ireton-Jones, and the maximum value $(25 \mathrm{kcal} / \mathrm{kg} /$ day $)$ of the European Society for Clinical Nutrition and Metabolism (ESPEN) equations, have been established and validated for estimating REE in various clinical states [9-13].

In the current study, we compared the REE measured by IC with that calculated using the five abovementioned PEs. We sought to determine which of these equations better reflected the REE measured by IC in patients with severe trauma.

\section{METHODS}

This was a retrospective, observational, and analytical study. All patients were admitted to the trauma intensive care unit (ICU) at Gachon University Gil Medical Center from January to December 2015. This study was approved by the Research Ethics Committee of Research and Education. The need for informed consent was waived because additional procedures were not performed except for routine intensive care, and the data collection did not exceed the normal risk of harm to the participant. This study was approved by the Institutional Review Board of the Gil Medical Center of Gachon University College of Medicine (IRB No. GCIRB2017-389). Informed consent was waived by The Ethics Committee of Gil Medical Center of Gachon University College of Medicine. Our work does not infringe on the rights of others, including privacy rights and intellectual property rights. There were no human rights violations in our study.

Mechanically ventilated patients in whom REE was measured by IC were enrolled. This study was designed to include patients aged $>18$ years with an Injury Severity Score (ISS) of $>15$. The fraction of inspired oxygen $\left(\mathrm{FiO}_{2}\right)$ was 0.6 or less while measuring REE with IC. Patients with $\mathrm{FiO}_{2}>0.6$ on the ventilator settings or a respiratory quotient $(\mathrm{RQ})$ outside of the physiological range were excluded. IC was performed using a CCM Express ${ }^{\circledR}$ indirect calorimeter (MGC Diagnostics, St. Paul, MN, USA). The calorimeter was operated during the study period by two

Table 1. Five predictive equations for calculating REE in this study

\begin{tabular}{|c|c|c|}
\hline & Factors & Calculation of REE \\
\hline Harris-Benedict ( $\times 1.2)$ & Gender, weight, age, height & $\begin{array}{l}\text { (M) } 66.47+(13.75 \times w t)+(5.0 \times h t)-(6.75 \times a g e) \\
\text { (W) } 655.1+(9.56 \times w t)+(1.85 \times h t)-(4.68 \times a g e)\end{array}$ \\
\hline Ireton-Jones & Gender, age, weight, trauma, burn & 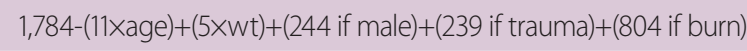 \\
\hline Fleisch & Gender, age, BSA & $\begin{array}{l}\text { (M) } 24 \times B S A \times(38-0.073 \times[\text { age-20] }) \\
\text { (W) } 24 \times B S A \times(35.5-0.064 \times[\text { age-20]) }\end{array}$ \\
\hline Robertson and Reid & Gender, age, BSA & $\mathrm{BSA} \times 24 \times$ value in table \\
\hline ESPEN (maximum value) & Weight & 25 kcalxwt \\
\hline
\end{tabular}

REE: resting energy expenditure, ESPEN: European Society for Clinical Nutrition and Metabolism, wt: weight, ht: height, BSA: body surface area. 
dedicated members of our nutritional support team, who had expertise in the technique. The patients were sedated and maintained at -2 on the Richmond agitation-sedation scale (RASS) during the evaluation. The REE measurement by IC was performed 15 minutes after reaching a steady state of -2 on the RASS.

Demographic data of the patients were obtained at the time of ICU admission. Body mass index (BMI) was calculated using the following formula: $\mathrm{BMI}=$ weight $(\mathrm{kg}) /$ height squared $\left(\mathrm{m}^{2}\right)$. Body surface area (BSA) was calculated using the Du Bois formula [14]: BSA $\left(\mathrm{m}^{2}\right)=0.007184 \times$ weight $^{0.425}(\mathrm{~kg}) \times$ height $^{0.725}(\mathrm{~cm})$. The REE was estimated using five predictive methods: the Harris and Benedict, Fleisch, Robertson and Reid, and Ireton-Jones equations, and the ESPEN maximum value (Table 1).

Statistical analyses were performed using SPSS version 19.0 (IBM Corp., Armonk, NY, USA). Data were reported as means \pm standard deviations (SD) or as medians and interquartile ranges, as appropriate. The paired $t$-test was used to evaluate the differences between the measured REE and that calculated by PEs. The Bland-Altman meth-

Table 2. Demographic data of patients $(n=31)$

\begin{tabular}{|lc|}
\hline Age (years) & $\mathbf{4 9 . 7 \pm 1 3 . 2 ( 2 3 - 7 6 )}$ \\
\hline Male & $24(77.4)$ \\
Weight $(\mathrm{kg})$ & $68.1 \pm 9.6$ \\
Height $(\mathrm{cm})$ & $167.6 \pm 7.7$ \\
$\mathrm{BMl}\left(\mathrm{kg} / \mathrm{m}^{2}\right)$ & $24.7 \pm 3.1$ \\
$\mathrm{BSA}\left(\mathrm{m}^{2}\right)$ & $1.77 \pm 0.15$ \\
Trauma mechanism & \\
Blunt & $26(83.9)$ \\
Stab & $5(16.1)$ \\
Nutrition support state NPO & $19(61.3)$ \\
Time lag from trauma (day) & $3.6 \pm 1.9(2-8)$ \\
FiO 2 & $38.72 \pm 6.97$ \\
RQ & $0.93 \pm 0.19$ \\
Injury Severity Score & $26.1 \pm 11.3$ \\
Duration of ventilator (day) & $10.2 \pm 6.0$ \\
Duration of ICU stay (day) & $16.8 \pm 13.8$ \\
\hline
\end{tabular}

Values are presented as mean \pm standard deviation or number (\%). BMl: body mass index, BSA: body surface area, NPO: nil per os, RQ: respiratory quotient, ICU: intensive care unit. od was used to calculate the mean difference in REE measured by IC with that calculated using PEs. For each PE, accuracy was defined as an estimated value within $\pm 10 \%$ of the measured REE for an individual. Statistical significance was set at $p<0.05$.

\section{RESULTS}

The demographic data are shown in Table 2. A total of 31 patients (male/female: 24/7) were included in this study. All patients were aged $>18$ years, with a mean age of $49.7 \pm 13.2$ years. Their mean BMI was $24.7 \pm 3.1 \mathrm{~kg} / \mathrm{m}^{2}$, and their mean BSA was $1.77 \pm 0.15 \mathrm{~m}^{2}$. The mean duration of ventilator use was $10.2 \pm 6.0$ days, and the mean duration of the ICU stay was $16.8 \pm 13.8$ days. Among the 31 patients, 26 (83.9\%) had blunt injuries and five (16.1\%) had penetrating injuries (stab wounds). The mean ISS was 26.1 \pm 11.3 . The ISS was $>15$ in all patients. The mean time lag from trauma until measurement of the IC was 3.6 \pm 1.9 days, and most patients had IC measurements made within 7 days. The ventilator status of all patients was stable within an $\mathrm{FiO}_{2}$ of $60 \%$, with a mean of $38.72 \pm 6.97 \%$. The mean RQ was $0.93 \pm 0.19$. On ICU admission, $61.2 \%$ of the patients underwent an emergency operation, $25.8 \%$ underwent laparotomy, and $12.9 \%$ underwent thoracotomy. Table 3 shows a comparison of the measured and predicted REE values. The mean REE measured by IC was $2,146 \pm 444.36 \mathrm{kcal} / \mathrm{day}$, and the mean REE calculated

Table 3. Comparison of REE between indirect calorimetry and predictive equations

\begin{tabular}{|lccc|}
\hline Variable & $\begin{array}{c}\text { Value } \\
\text { (kcal/day) }\end{array}$ & $\begin{array}{c}\text { Value } \\
\text { (kcal/kg) }\end{array}$ & p-value \\
\hline Indirect calorimetry & $2,146.48 \pm 444.36$ & $31.83 \pm 7.16$ & \\
Harris-Benedict & $1,509.39 \pm 205.34$ & $22.21 \pm 1.77$ & 0.006 \\
Fleisch & $1,512.23 \pm 154.33$ & $22.34 \pm 1.79$ & 0.003 \\
Robertson-Reid & $1,443.39 \pm 159.61$ & $21.31 \pm 1.76$ & $<0.001$ \\
Ireton-Jones & $2,278.90 \pm 202.35$ & $33.84 \pm 4.17$ & 0.053 \\
$\begin{array}{l}\text { ESPEN maximum } \\
\text { (25 kcal/kg) }\end{array}$ & $1,704.03 \pm 449.36$ & 25 & 0.127 \\
\hline
\end{tabular}

REE: resting energy expenditure, ESPEN: European Society for Clinical Nutrition and Metabolism. 
by the PEs was $1,509.39 \pm 205.34 \mathrm{kcal} /$ day for the Harris and Benedict question, $1,509.39 \pm 154.33 \mathrm{kcal} / \mathrm{day}$ for the Fleisch equation, and 1,443.39 $\pm 159.61 \mathrm{kcal} /$ day for the Robertson and Reid equation. These three PEs yielded estimated REEs that were significantly lower than the REE measured by IC ( $p=0.006, p=0.003$, and $p<0.001$, respectively). The Ireton-Jones equation yielded a higher value $(2,278.90 \pm 202.35 \mathrm{kcal} /$ day $)$ than the measured REE, but the difference was not significant $(p=0.053)$. The ESPEN maximum value $(1,704.03 \pm 449.36 \mathrm{kcal})$ was lower, but the difference was not significant $(p=0.127)$. Fig. 1 shows the measured and calculated REE of each individual. Fig. 2 shows the Spearman's correlation coefficients and a scatter plot graph between the IC and each PE. All PEs revealed a positive correlation with IC $(0.264 \leq r \leq 0.521)$. The Ireton-Jones equation showed the highest correlation with IC ( $\mathrm{r}=0.521)$, while ESPEN had the lowest correlation $(\mathrm{r}=0.264)$.

In terms of the agreement of the PEs with IC at the individual level, the Harris-Benedict, Fleisch, and Robertson-Reid equations revealed similar results in this study (Harris-Benedict, 9.6\% agreement and 90.4\% underestimation; Fleisch, 9.5\% and 90.4\%; and Robertson and Reid, $6.5 \%$ and $93.4 \%$, respectively). The ESPEN maximum value $(25 \mathrm{kcal} / \mathrm{kg}$ ) agreed with IC in $25.8 \%$ of cases and was an underestimation in $74.2 \%$ of cases. Unlike the other equations, the Ireton-Jones equation showed agreement in $41.9 \%$ of cases, overestimation in $45.1 \%$, and underestimation in $12.9 \%$. Fig. 3 shows the Bland-Altman plot for REE between the five PEs and IC. All five predictive equations showed fixed bias in the Bland-Altman plot.

\section{DISCUSSION}

Nutritional support must be based on an accurate assessment of the patient's energy expenditure (EE) to avoid complications associated with inadequate nutritional support [1-5]. An individual's EE is generally assessed by estimating the REE, which accounts for approximately $70 \%$ of the total EE. The REE can be estimated by using PEs or IC [6]. The calculated REE based on PEs could have limitations in fully responding to physiological and metabolic variability with regard to its application in practical nutrition. Various environmental conditions and physiological factors affect EE [15]. Measuring REE using IC, which quantifies oxygen consumption and carbon dioxide production, provides a more accurate approximation of EE $[5,7,8,16]$. Several studies have compared IC with PEs in various medical conditions [17-19].

Despite the standardization of REE measurements by IC in various clinical situations, few studies have compared the REE as assessed by PEs and IC, specifically in severe trauma patients with mechanical ventilation. In 1996, Monk et al. [20] evaluated sequential changes in the metabolic response after blunt trauma, including 10 patients on a ventilator. Among their results, it was

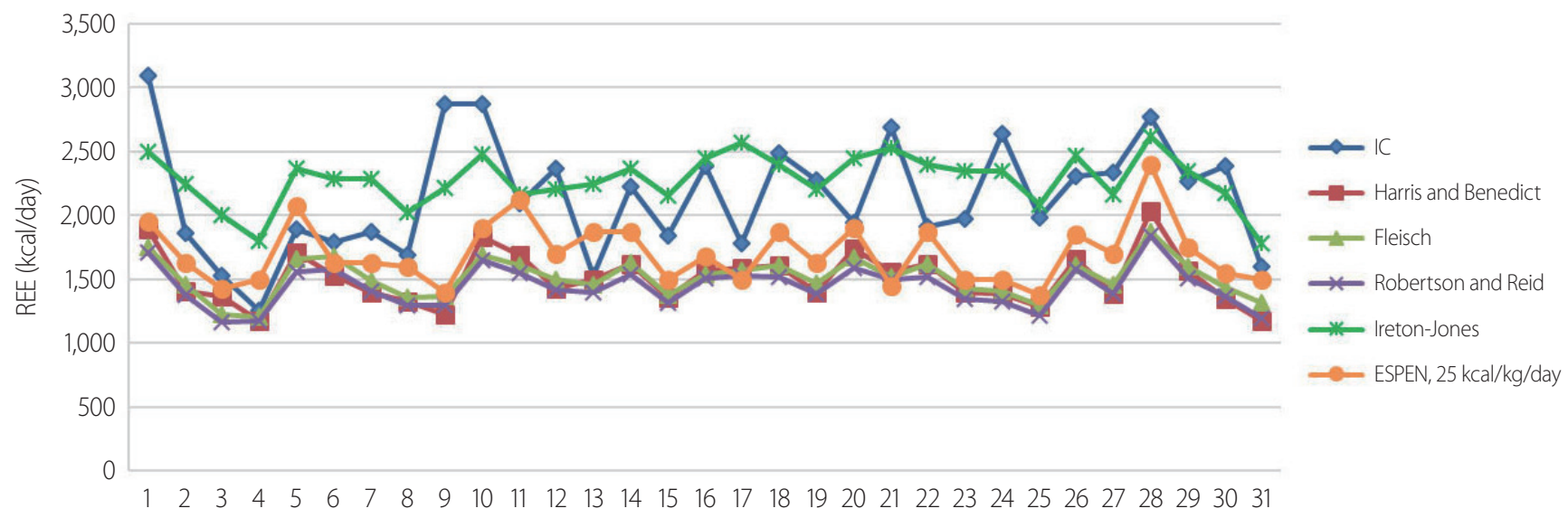

Fig. 1. The measured and calculated REE of individuals. REE: resting energy expenditure, IC: indirect calorimetry, ESPEN: European Society for Clinical Nutrition and Metabolism. 

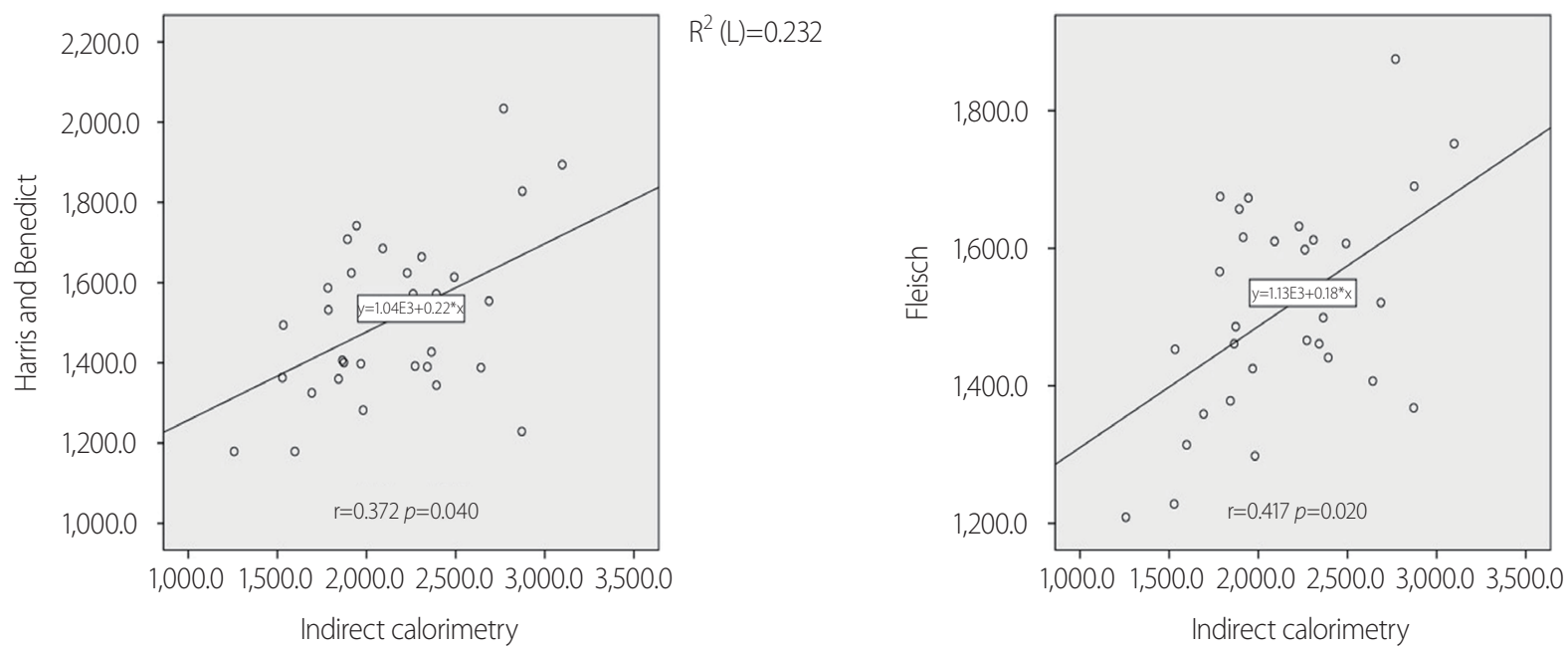

$R^{2}(L)=0.263$

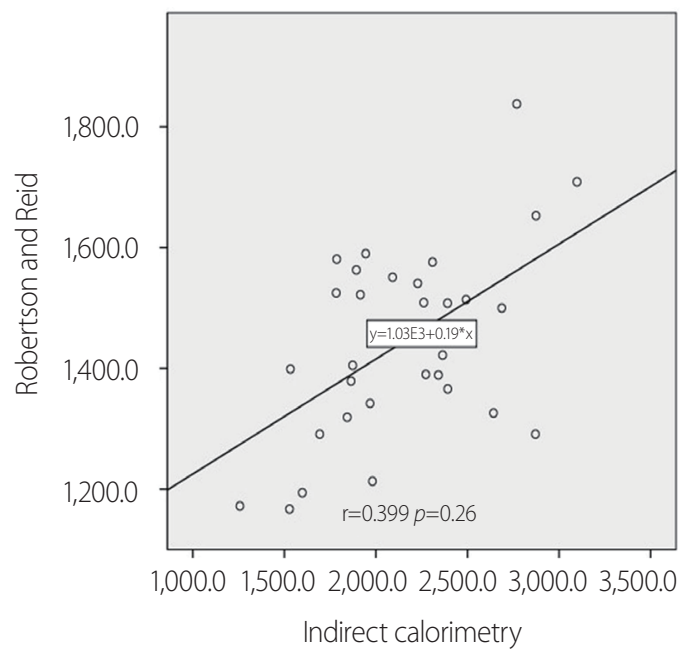

$R^{2}(L)=0.2$

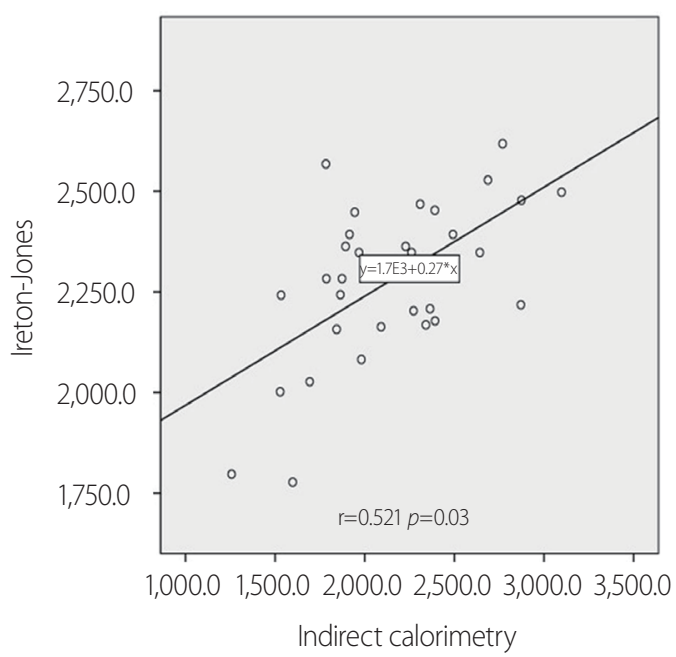

$R^{2}(L)=0.362$

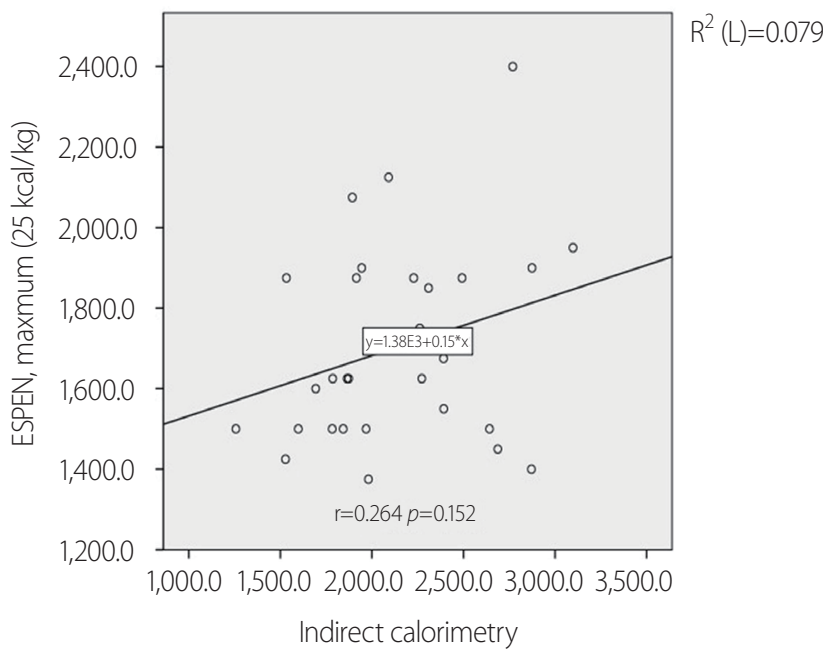

Fig. 2. Spearman's correlation coefficients and scatter plot graph between the IC and each PE. IC: indirect calorimetry, ESPEN: European Society for Clinical Nutrition and Metabolism, PE: prediction equation. 


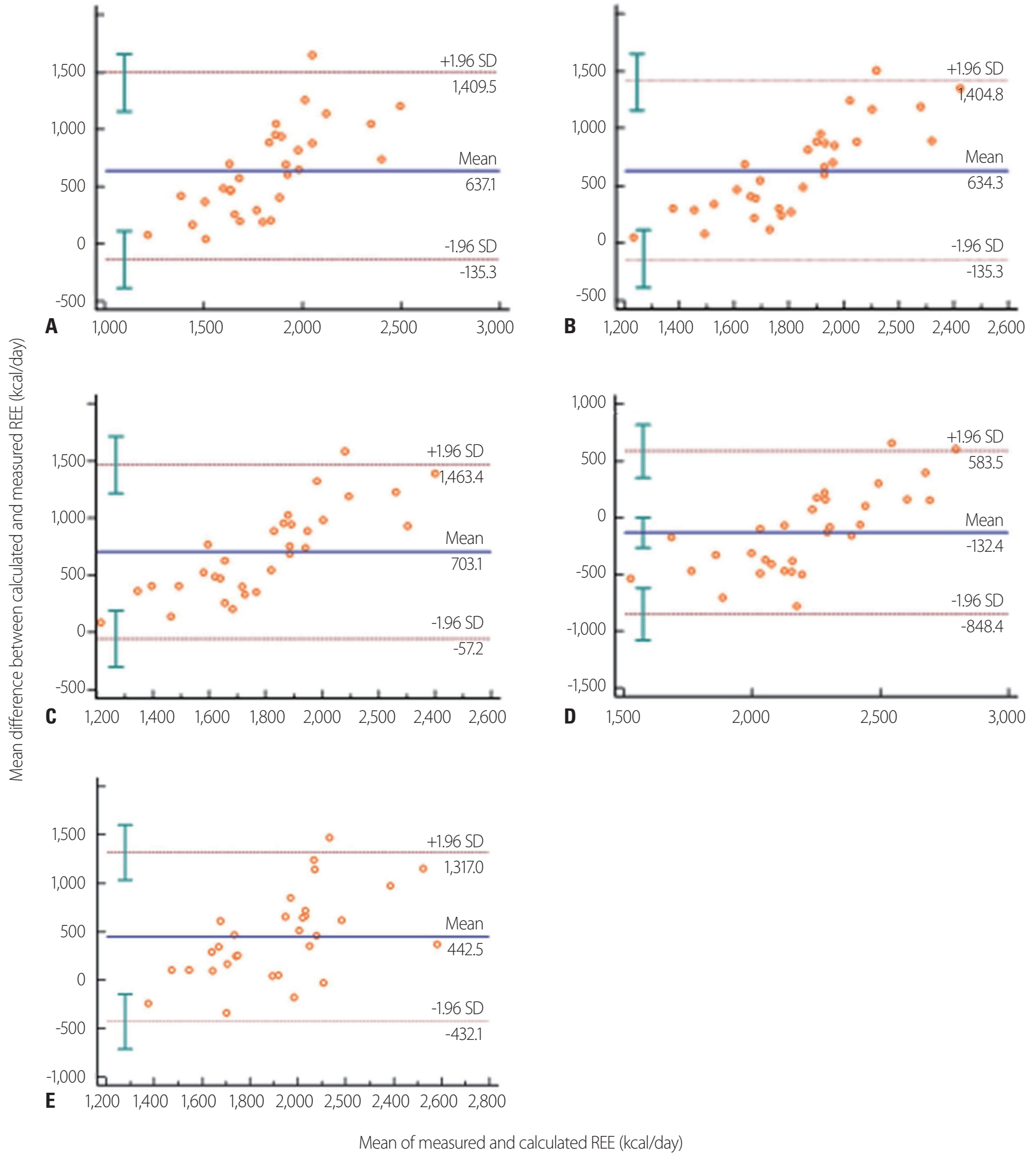

Fig. 3. Bland-Altman plots comparing predictive equations and measured energy expenditure by indirect calorimetry: (A) Harris-Benedict method; (B) the Fleisch equation; (C) the Robertson and Reid equation; (D) the Ireton-Jones equation; (E) the ESPEN maximum value (25 kcal/kg). The middle dashed horizontal line represents the absolute bias (mean difference between the two methods in kcal/day). The upper and lower dashed lines depict the $95 \%$ limits of agreement (mean difference \pm 1.96 SD). REE, resting energy expenditure, SD: standard deviations, ESPEN: European Society for Clinical Nutrition and Metabolism. 
reported that measured REE was significantly higher than predicted REE, averaging 55\% above the predicted value. In 2000, Plank and Hill [1] also reported similar results in 12 patients with severe trauma, where REE was measured by IC as the ratio to the predicted REE; they found that the ratio increased over the first 4 to 5 days and peaked around days 9 to 12 , with a peak ratio of $1.60 \pm 0.13$ during trauma. The above-mentioned studies showed similar results for patients with severe trauma, as the measured REEs were higher than the calculated REEs for a certain period after trauma.

Although the accuracy and reliability of REE using IC have been accepted, its use is limited in clinical settings because of personnel qualifications, logistics, and economic issues [16]. Thus, calculating the REE using PEs is still an available method.

In this study, we evaluated the accuracy of five commonly used PEs against measured REE in 31 patients with severe trauma (ISS $>15$ ) on ventilators in the ICU. The correlation between each PE and the REE measurement was positive and significant $(r \geq 0.372, p \leq 0.040)$, with the exception of the ESPEN maximum value $(\mathrm{r}=0.264$, $p=0.152$ ). The Ireton-Jones equation was the PE with the highest accuracy in comparison with the IC values (41.9\%). In a comparison of the mean REE values using the paired t-test, as shown in Table 2, the estimated REE using PEs presented relatively lower values except for the Ireton-Jones equation. Our data showed that all of the equations, except the Ireton-Jones equation, underestimated REE in severe trauma patients.

There are some limitations to this study. First, this was a retrospective study with a small sample. Second, we were unable to simultaneously obtain body weight while measuring REE with IC. This may have influenced the difference in the final REE values obtained using PEs in this study. Third, each subject was measured once; therefore, it was not possible to estimate intra-individual variation in REE. Fourth, although all participants in this study were trauma patients, we could not identify the impact of specific injury patterns on energy requirements individually. Sixth, this study did not assess clinical outcomes according to the REE.

\section{CONCLUSION}

The REE measured by IC was relatively higher than the REE calculated by PEs, except for the REE calculated using the Ireton-Jones equation. We recommend using IC when assessing caloric requirements after trauma, as in our study group. Further development of more practical methods that can accurately predict energy needs is desirable.

\section{REFERENCES}

1. Plank LD, Hill GL. Sequential metabolic changes following induction of systemic inflammatory response in patients with severe sepsis or major blunt trauma. World J Surg 2000;24:6308.

2. Biffl WL, Moore EE, Haenel JB. Nutrition support of the trauma patient. Nutrition 2002;18:960-5.

3. Sena MJ, Utter GH, Cuschieri J, Maier RV, Tompkins RG, Harbrecht BG, et al. Early supplemental parenteral nutrition is associated with increased infectious complications in critically ill trauma patients. J Am Coll Surg 2008;207:459-67.

4. Shi HP. Metabolic response and dynamic nutrition support after trauma. Zhonghua Shao Shang Za Zhi 2013;29:335-7.

5. Tatucu-Babet OA, Ridley EJ, Tierney AC. Prevalence of underprescription or overprescription of energy needs in critically ill mechanically ventilated adults as determined by indirect calorimetry: a systematic literature review. JPEN J Parenter Enteral Nutr 2016;40:212-25.

6. Dellava JE, Hoffman DJ. Validity of resting energy expenditure estimated by an activity monitor compared to indirect calorimetry. Br J Nutr 2009;102:155-9.

7. McClave SA, Martindale RG, Kiraly L. The use of indirect calorimetry in the intensive care unit. Curr Opin Clin Nutr Metab Care 2013;16:202-8.

8. Allingstrup MJ, Kondrup J, Perner A, Christensen PL, Jensen $\mathrm{TH}$, Henneberg SW. indirect calorimetry in mechanically ventilated patients: a prospective, randomized, clinical validation of 2 devices against a gold standard. JPEN J Parenter Enteral Nutr 2017;41:1272-7.

9. Harris JA, Benedict FG. A biometric study of human basal metabolism. Proc Natl Acad Sci U S A 1918;4:370-3.

10. Fleisch A. Basal metabolism standard and its determination 
with the "metabocalculator". Helv Med Acta 1951;18:23-44.

11. Robertson JD, Reid DD. Standards for the basal metabolism of normal people in Britain. Lancet 1952;1:940-3.

12. Ireton-Jones $\mathrm{C}$, Jones JD. Improved equations for predicting energy expenditure in patients: the Ireton-Jones Equations. Nutr Clin Pract 2002;17:29-31.

13. Singer P, Berger MM, Van den Berghe G, Biolo G, Calder P, Forbes A, et al. ESPEN guidelines on parenteral nutrition: intensive care. Clin Nutr 2009;28:387-400.

14. Du Bois D, Du Bois EF. A formula to estimate the approximate surface area if height and weight be known. 1916. Nutrition 1989;5:303-11; discussion 312-3.

15. Moonen HPFX, Beckers KJH, van Zanten ARH. Energy expenditure and indirect calorimetry in critical illness and convalescence: current evidence and practical considerations. J Intensive Care 2021;9:8

16. Haugen HA, Chan LN, Li F. Indirect calorimetry: a practical guide for clinicians. Nutr Clin Pract 2007;22:377-88.

17. Kee AL, Isenring E, Hickman I, Vivanti A. Resting energy expenditure of morbidly obese patients using indirect calorimetry: a systematic review. Obes Rev 2012;13:753-65.

18. Aliasgharzadeh S, Mahdavi R, Asghari Jafarabadi M, Namazi N. Comparison of indirect calorimetry and predictive equations in estimating resting metabolic rate in underweight females. Iran J Public Health 2015;44:822-9.

19. Tancheva D, Arabadziev J, Gergov G, Lachev N, Todorova S, Hristova A. Comparison of estimated energy requirements in severely burned patients with measurements by using indirect calorimetry. Ann Burns Fire Disasters 2005;18:16-8.

20. Monk DN, Plank LD, Franch-Arcas G, Finn PJ, Streat SJ, Hill GL. Sequential changes in the metabolic response in critically injured patients during the first 25 days after blunt trauma. Ann Surg 1996;223:395-405. 